\title{
Sight-Threatening Graves' Ophthalmopathy during the Third Trimester of Pregnancy: A Case Report
}

\author{
Kanako Sakurai, ${ }^{1}$ Toshu Inoue, ${ }^{2}$ Satsuki Niitsuma, ${ }^{1}$ Ryota Sato, ${ }^{1}$ \\ Kazuhiro Takahashi ${ }^{3}$ and Zenei Arihara ${ }^{1}$ \\ ${ }^{1}$ Department of Endocrinology and Metabolism, National Hospital Organization Sendai Medical Center, Sendai, \\ Miyagi, Japan \\ ${ }^{2}$ Olympia Eye Hospital, Tokyo, Japan \\ ${ }^{3}$ Department of Endocrinology and Applied Medical Science, Tohoku University Graduate School of Medicine, \\ Sendai, Miyagi, Japan
}

\begin{abstract}
Dysthyroid optic neuropathy is a severe manifestation of Graves' ophthalmopathy that can result in permanent vision loss. We report a 37-year-old pregnant woman with Graves' ophthalmopathy which was deteriorated to dysthyroid optic neuropathy in the third trimester of pregnancy. Diplopia, bilateral eye lid retraction, lid edema and proptosis were observed in the 29th week of gestation. Thyroid-stimulating hormone (TSH) level was decreased with a normal level of free triiodothyronine (FT3) and an upper normal level of free thyroxine (FT4). Anti-TSH receptor antibodies (16.2 IU/L, reference range < $2.0 \mathrm{IU} / \mathrm{L})$ and thyroid stimulating antibody $(4,443 \%$, reference range $<120 \%)$ were positive. Magnetic resonance imaging (MRI) demonstrated a significant enlargement of the extraocular muscles with a high signal intensity on T2-weighted image. She was diagnosed as Graves' ophthalmopathy and subclinical hyperthyroidism, and followed without treatment. In the 34th week of gestation, the symptom of color vision abnormality appeared, suggesting dysthyroid optic neuropathy. She delivered a female infant during the 36th week of gestation. Four days after delivery, she had a spontaneous orbital pain. MRI showed that the extraocular muscles were more enlarged than the findings in the 29th week of gestation. FT3 and FT4 levels were mildly elevated. Dysthyroid optic neuropathy was diagnosed. She was treated with methylprednisolone pulse therapy and retrobulbar injections of betamethasone valerate, and the ocular symptoms improved. The present case shows that the glucocorticoid therapy performed one week after delivery is effective against Graves' ophthalmopathy which was deteriorated to dysthyroid optic neuropathy during the third trimester of pregnancy.
\end{abstract}

Keywords: anti-thyroid-stimulating hormone receptor antibodies; clinical activity score; Graves' ophthalmopathy; pregnancy; thyroid stimulating antibody

Tohoku J. Exp. Med., 2020 December, 252 (4), 321-327.

\section{Introduction}

Graves' ophthalmopathy is an autoimmune disorder affecting the orbital fat and extraocular muscles. It is closely associated with autoimmune thyroid disease, and generally occurs in patient with hyperthyroidism or a history of hyperthyroidism (Bartalena et al. 2000; Bartalena and Tanda 2009; Bahn 2010). However, it may occur in patients without current or prior hyperthyroidism (euthyroid or ophthalmic Graves' disease) or in patients who are hypothyroid due to chronic autoimmune thyroiditis (Marcocci et al. 1989; Burch and Wartofsky 1993).

Approximately $50 \%$ of patients with Graves' disease will suffer from Graves' ophthalmopathy. Mild or moderate Graves' ophthalmopathy is the most common presentation whereas sight-threatening Graves' ophthalmopathy affects $3 \%$ to $5 \%$ of patients with Graves' ophthalmopathy (Wiersinga and Bartalena 2002; Tramunt et al. 2019), and includes two different entities; dysthyroid optic neuropathy and corneal ulcer. Over $90 \%$ of patients with dysthyroid optic neuropathy are related to nerve compression by enlarged extraocular muscles while the remainder are

Received September 17, 2020; revised and accepted November 12, 2020. Published online December 2, 2020; doi: 10.1620/tjem.252.321. Correspondence: Kanako Sakurai, Department of Endocrinology and Metabolism, National Hospital Organization Sendai Medical Center, 2-11-12 Miyagino, Miyagino-ku, Sendai, Miyagi 983-8520, Japan.

e-mail: kanasakurai-dm@umin.ac.jp

(C)2020 Tohoku University Medical Press. This is an open-access article distributed under the terms of the Creative Commons Attribution-NonCommercial-NoDerivatives 4.0 International License (CC-BY-NC-ND 4.0). Anyone may download, reuse, copy, reprint, or distribute the article without modifications or adaptations for non-profit purposes if they cite the original authors and source properly.

https://creativecommons.org/licenses/by-nc-nd/4.0/ 
caused by stretching of the optic nerve without compression (Dolman 2020). Clinical features of dysthyroid optic neuropathy may include reduction in central and color vision, afferent pupil defect and/or optic disc edema (Dolman 2020).

The course of Graves' disease is altered during pregnancy. Clinical features of Graves' disease exacerbate in the first trimester, improve in the second and third trimesters, and rebound in the postpartum period (Mestman et al. 1995; Rotondi et al. 2008). However, it is unclear whether the clinical features of Graves' ophthalmopathy improve or get worse during pregnancy.

Here we report a pregnant woman with Graves' ophthalmopathy and subclinical hyperthyroidism diagnosed in the third trimester of pregnancy. In this case, the clinical features of Graves' ophthalmopathy were deteriorated to dysthyroid optic neuropathy, sight-threatening Graves' ophthalmopathy, during the third trimester.

\section{Case Presentation}

A 37-year-old woman (gravida 1, para 1) was referred to our hospital in the 29th week of gestation with a symptom of diplopia. The prenatal course of the pregnancy was uneventful until the 29th week of gestation, when she noted the sudden onset of diplopia and visited to our hospital.

Her past medical history was unremarkable. She had no histories of brain diseases, endocrinological diseases or autoimmune diseases. Her family history was negative for thyroid diseases. She was a non-smoker, and a non-drinker.

Physical examination revealed bilateral eye lid retractions, eye lid edema, and proptosis. Conjunctival injection was absent. Blood pressure was $135 / 66 \mathrm{mmHg}$, and the pulse rate was $84 / \mathrm{min}$. The thyroid function test showed a decreased level of thyroid-stimulating hormone (TSH) $(0.008 \mu \mathrm{U} / \mathrm{mL}$, reference range $0.55-4.78 \mu \mathrm{U} / \mathrm{mL})$, a normal level of free triiodothyronine (FT3) $(3.68 \mathrm{pg} / \mathrm{mL}$, reference range $2.13-4.07 \mathrm{pg} / \mathrm{mL}$ ), and an upper normal level of free thyroxine (FT4) $(1.71 \mathrm{ng} / \mathrm{dL}$, reference range $0.95-1.74 \mathrm{ng} /$ dL). Anti-TSH receptor antibodies (TRAb) (16.2 IU/L, reference range $<2.0 \mathrm{IU} / \mathrm{L})$ and thyroid stimulating antibody (TSAb) $(4,443 \%$, reference range $<120 \%)$, anti-thyroglobulin antibodies $(1,130 \mathrm{IU} / \mathrm{mL}$, reference range $<28 \mathrm{IU} / \mathrm{mL})$ and anti-thyroid peroxidase antibodies $(192 \mathrm{IU} / \mathrm{mL}$, reference range $<16 \mathrm{IU} / \mathrm{mL}$ ) were all positive. Thyroid ultrasonography demonstrated a diffuse goiter with increased blood flow signal (data not shown). Serum C-reactive protein was normal $(0.0 \mathrm{mg} / \mathrm{dL}$; reference range $<0.3 \mathrm{mg} / \mathrm{dL})$. Laboratory test results at the first visit of our hospital are summarized in the Table 1. Magnetic resonance imaging (MRI) of orbital region demonstrated a significant enlargement of the extraocular muscles (especially right internal rectus muscle, right superior rectus muscle, and left internal rectus muscle) that is characteristics of Graves' ophthalmopathy. In addition, high signal intensities were observed in the extraocular muscles on T2-weighted image, indicating the occurrence of inflammation in the extraocular mus-
Table 1. Laboratory test results at the first visit of our hospital.

$\begin{array}{lcc}\text { White blood cell } & 8,800 / \mu \mathrm{L} & (3,500-9,000) \\ \text { Red blood cell } & 418 \times 10^{3} / \mu \mathrm{L} & \left(380-500 \times 10^{3}\right) \\ \text { Hemoglobin } & 12 \mathrm{~g} / \mathrm{dL} & (11.3-15.2) \\ \text { Hematocrit } & 37 \% & (33-45) \\ \text { Platelet } & 26.2 \times 10^{4} / \mu \mathrm{L} & \left(13-37 \times 10^{4}\right) \\ \text { Total protein } & 6.2 \mathrm{~g} / \mathrm{dL} & (6.7-8.3) \\ \text { Albumin } & 3.1 \mathrm{~g} / \mathrm{dL} & (3.8-5.3) \\ \text { AST } & 14 \mathrm{IU} / \mathrm{L} & (7-38) \\ \text { ALT } & 12 \mathrm{IU} / \mathrm{L} & (4-43) \\ \text { Alkaline Phosphatase } & 424 \mathrm{IU} / \mathrm{L} & (104-338) \\ \gamma \text { GTP } & 12 \mathrm{IU} / \mathrm{L} & (10-63) \\ \text { Creatinine } & 0.31 \mathrm{mg} / \mathrm{dL} & (0.47-0.79) \\ \text { TSH } & 0.008 \mu \mathrm{U} / \mathrm{mL} & (0.55-4.78) \\ \text { FT3 } & 3.68 \mathrm{pg} / \mathrm{mL} & (2.13-4.07) \\ \text { FT4 } & 1.71 \mathrm{ng} / \mathrm{dL} & (0.95-1.74) \\ \text { C-reactive protein } & 0 \mathrm{mg} / \mathrm{dL} & (<0.3) \\ \text { TSH receptor antibody } & 16.2 \mathrm{IU} / \mathrm{L} & (<2.0) \\ \text { TSAb } & 4,443 \% & (<120) \\ \text { Anti-thyroglobulin antibody } & 1,130 \mathrm{IU} / \mathrm{mL} & (0-28) \\ \text { Anti-thyroid peroxidase antibody } & 192 \mathrm{IU} / \mathrm{mL} & (0-16) \\ \text { Fasting plasma glucose } & 97 \mathrm{mg} / \mathrm{dL} & \\ \text { HbA1c } & 5.4 \% & \\ & & \end{array}$

The ranges of reference values are indicated in the parentheses.

AST, aspartate aminotransferase; ALT, alanine aminotransferase; $\gamma \mathrm{GTP}, \gamma$-Glutamyltranspeptidase; TSH, thyroid stimulating hormone; FT3, free triiodothyronine; FT4, free thyroxine; TSAb, thyroid-stimulating antibodies; HbA1c, Hemoglobin A1c.

cles (Fig. 1A). Graves' ophthalmopathy was diagnosed with subclinical hyperthyroidism.

The ophthalmopathy was assessed by a clinical activity score (CAS) (CAS ranges from 0 to 7 points, and CAS $\geq$ 3 means active ophthalmopathy), and European Group on Graves' Orbitopathy (EUGOGO) classification of the severity of the ophthalmopathy (Bartalena et al. 2008). Her CAS was 2 points, and EUGOGO classification of severity was moderate to severe. Based on these findings, methylprednisolone pulse therapy was considered as a choice of the treatment of Graves' ophthalmopathy. Methylprednisolone pulse therapy was not done, however, because of its possible adverse effects during pregnancy (Guller et al. 1995; Lockwood et al. 1996; Park-Wyllie et al. 2000; Thorp et al. 2002; Reynolds 2013).

In addition, we did not start the treatment with antithyroid drugs for the following reasons. First, FT4 level was an upper normal level, and the patient had no symptoms of hyperthyroidism. The second reason was possible adverse effects of anti-thyroid drugs, including fulminant liver injury and agranulocytosis during pregnancy. Moreover, signs of fetal hyperthyroidism were not detected on ultrasonography, such as fetal tachycardia, intrauterine 


\section{(A) \\ 29th week of gestation}

\section{( B ) \\ 1 week after delivery (Before methylprednisolone pulse therapy)}

\section{( C ) 6 weeks after delivery (2 weeks after methylprednisolone pulse therapy)}
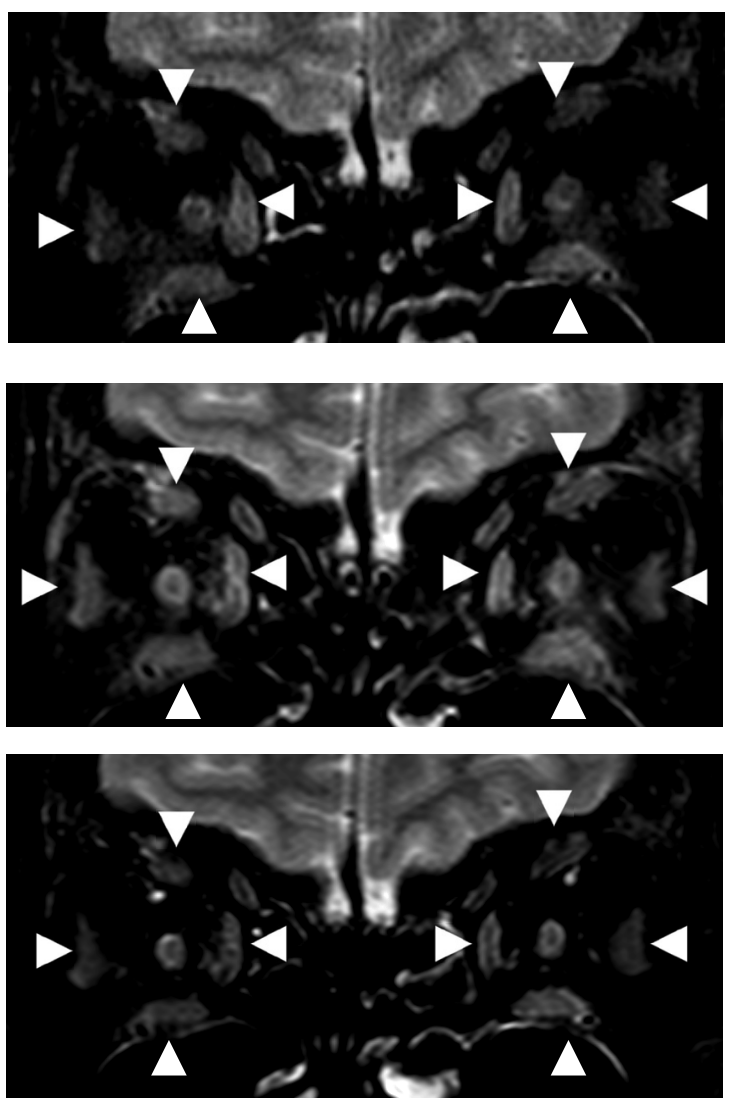

\section{( D ) 16 weeks after delivery} (3 months after methylprednisolone pulse therapy)

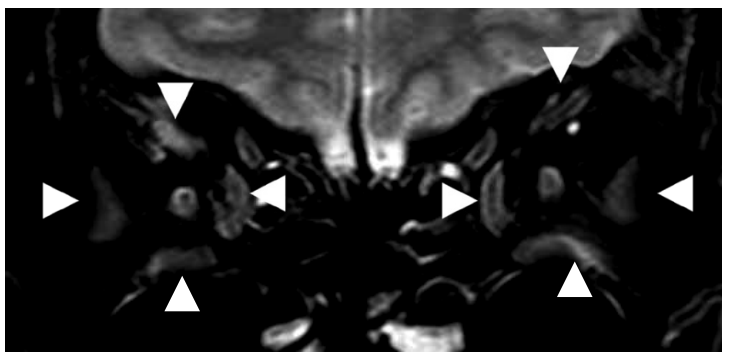

Fig. 1. Magnetic resonance imaging (MRI) of orbital region.

(A) 29th week of gestation. A significant enlargement of the extraocular muscles, and high signal intensities in the extraocular muscles (arrowheads) were observed on T2-weighted image. (B) One week after delivery (Before methylprednisolone pulse therapy). An enlargement of the extraocular muscles aggravated (arrowheads). (C) 6 weeks after delivery ( 2 weeks after methylprednisolone pulse therapy) and (D) 16 weeks after delivery ( 3 months after methylprednisolone pulse therapy). An enlargement of the extraocular muscles (arrowheads) improved after methylprednisolone pulse therapy.

growth restriction, and polyhydramnios. We were, therefore, concerned about possible adverse effects of anti-thyroid drugs on the fetus, such as hypothyroidism.

In the $32 \mathrm{nd}$ week of gestation, gestational diabetes mellitus was diagnosed, and treated with injection of insulin (9 units/day) before meal. In the 34th week of gestation, the symptom of color vision abnormality appeared, suggesting the possibility of dysthyroid optic neuropathy.

The breech presentation of the fetus was observed. Moreover, premature rupture of the membrane occurred with continuous labor in the 36th week of gestation. The emergent Caesarean section was therefore performed in the 36th week of gestation, and she delivered a 2,904 g female infant. The complications of the infant were hypocalcemia, hypoglycemia, neonatal Graves' disease, and dyspnea and apnea paroxysm of unknown cause.

Hypoglycemia and hypocalcemia $(\mathrm{Ca} 5.1 \mathrm{mg} / \mathrm{dL})$ of the infant were presumably due to gestational diabetes mellitus. Intravenous infusion of glucose solution was administered, and glucose levels were restored. Hypocalcemia was treated with intravenous or oral administration of calcium lactate $(1 \mathrm{~g} /$ day $)$. Serum Ca levels were recovered to $10.5 \mathrm{mg} / \mathrm{dL}$, and the administration of the calcium lactate was discontinued.

With respect to the neonatal Graves' disease, FT4 levels were slightly elevated (FT4 $2.16 \mathrm{ng} / \mathrm{dL}$ ) at the third day 


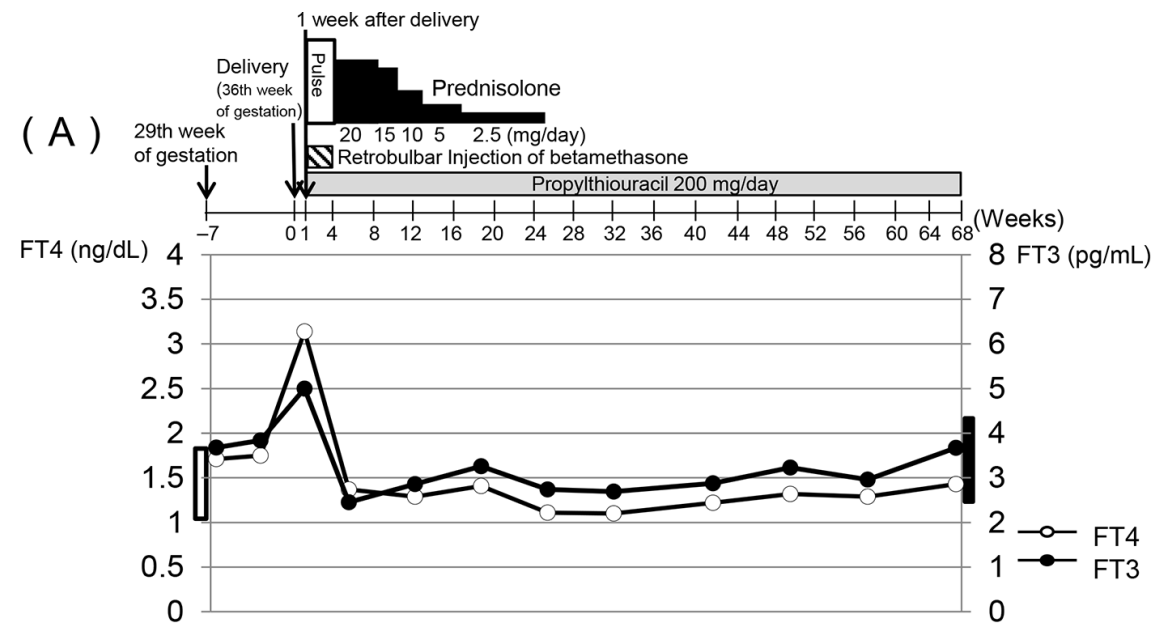

( B )

$\mathrm{TSH}(\mu \mathrm{U} / \mathrm{mL})$

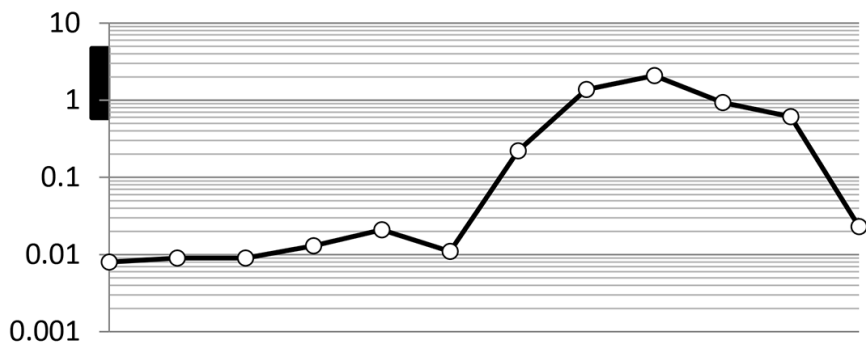

(C)

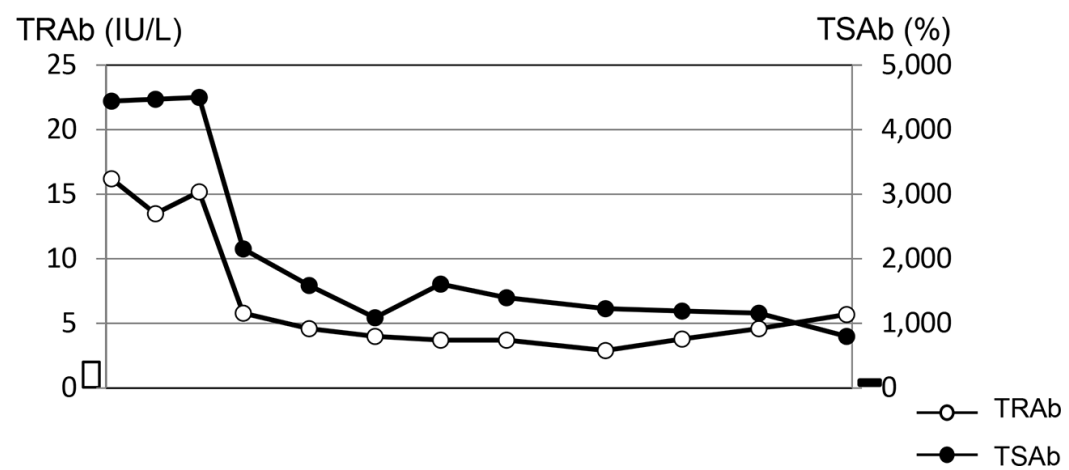

Fig. 2. Clinical course in the third trimester and the postpartum period.

Treatment and laboratory test results are shown. The day of the delivery was defined as Day 0 . (A) Serum levels of free thyroxine (FT4) (open circles) and free triiodothyronine (FT3) (closed circles). The open and closed bars on the left and right vertical axis denote the reference ranges for FT4 and FT3, respectively. Upper panel shows the treatment of methylprednisolone pulse therapy (Pulse) (methylprednisolone at $1,000 \mathrm{mg} /$ day given i.v. on 3 successive days weekly, and totally 3 cycles for 3 weeks), followed by a tapered dose of prednisolone, retrobulbar injections of betamethasone valerate (betamethasone valerate at $4 \mathrm{mg}$ /day to the right orbit for 4 days, and then every 2 days for 2 weeks) and propylthiouracil. Serum FT4 and FT3 levels drastically increased above the upper limit of the reference range one week after delivery, and administration of propylthiouracil $(200 \mathrm{mg} /$ day) was started. (B) Serum levels of thyroid-stimulating hormone (TSH). The closed bar on the left vertical axis denotes the reference range for TSH. TSH level was suppressed until 32 weeks after delivery, and normalized at 36 weeks after delivery. (C) Serum levels of anti-TSH receptor antibodies (TRAb) (open circles) and thyroid stimulating antibody (TSAb) (closed circle). The open and closed bars on the left and right vertical axis denote the reference ranges for TRAb and TSAb, respectively. After the glucocorticoid therapies and the initiation of propylthiouracil, the titers of the TRAb and TSAb decreased at 8 weeks after delivery, but remained to be still high thereafter.

after birth. FT4 levels recovered to normal level (FT4 1.65 $\mathrm{ng} / \mathrm{dL})$ at the 6th day after birth. TRAb levels were elevated $(3.7 \mathrm{IU} / \mathrm{L})$ at the third day after birth, and recovered to normal levels $(1.8 \mathrm{IU} / \mathrm{L})$ at the 6 th day after birth. FT3 and TSH levels were within the normal ranges at both the third and 6th days after birth. Dyspnea and apnea paroxysm continued until the 8th day after birth, but did not occur after the 9th day. 
Four days after delivery, she had a spontaneous orbital pain. We therefore reassessed the activity and the severity of the ophthalmopathy by CAS and EUGOGO classification of the severity of the ophthalmopathy. Her CAS was 3 points, and EUGOGO classification of severity was sightthreatening, indicating the diagnosis of dysthyroid optic neuropathy. A follow-up MRI of orbital region was performed 6 days after delivery, and showed that the extraocular muscles were more enlarged (Fig. 1B), and the areas of high signal intensities in the extraocular muscles on T2-weighted image were expanded compared with the MRI findings in the 29th week of gestation. She was treated with methylprednisolone pulse therapy (methylprednisolone at $1,000 \mathrm{mg}$ /day given i.v. on 3 successive days weekly, and totally 3 cycles for 3 weeks) (Fig. 2). Subsequently, she was treated with prednisolone at $20 \mathrm{mg}$ /day orally for 4 weeks, followed by a tapered dose of prednisolone $(15 \mathrm{mg} /$ day for 2 weeks, $10 \mathrm{mg} /$ day for 3 weeks, $5 \mathrm{mg}$ /day for 4 weeks, and then $2.5 \mathrm{mg} /$ day for 8 weeks). In addition, the retrobulbar injection of betamethasone valerate at $4 \mathrm{mg} /$ day was done to the right orbit for 4 days, followed by the retrobulbar injection at the same dose every 2 days for 2 weeks.

The symptom of the ophthalmopathy was improved after the methylprednisolone pulse therapy and retrobulbar injections of betamethasone valerate, except for downgazelimited diplopia of the right eye. She had no subjective symptom of color blindness after the treatment. Follow-up MRIs of orbital region which were performed 2 weeks (Fig. 1) and 3 months (Fig. 1D) after the methylprednisolone pulse therapy showed the improvement of enlargement of the extraocular muscles.

The thyroid function test showed hyperthyroidism one week after delivery (FT3 $5.00 \mathrm{pg} / \mathrm{mL}$, FT4 $3.14 \mathrm{ng} / \mathrm{dL}$ ). She was therefore treated with $200 \mathrm{mg} /$ day of propylthiouracil in addition to methylprednisolone pulse therapy. After the administration of propylthiouracil for 3 weeks, she recovered to the euthyroid state. After the glucocorticoid therapies and the initiation of propylthiouracil, the titers of the TRAb and TSAb decreased to $5.8 \mathrm{IU} / \mathrm{L}$ and $2,153 \%$, respectively, at 8 weeks after delivery, but remained to be still high thereafter.

Informed consent was obtained from the subject on this case report.

\section{Discussion}

We reported a pregnant woman with moderate-tosevere Graves' ophthalmopathy who was diagnosed in the third trimester. In this case, the clinical features of Graves' ophthalmopathy were deteriorated to dysthyroid optic neuropathy which may be sight-threatening during the third trimester. In addition, FT3 and FT4 levels were increased one week after delivery. Smoking is one major risk factor for Graves' ophthalmopathy (Wiersinga and Bartalena 2002). However, the present case was a non-smoker. Case reports on dysthyroid optic neuropathy during pregnancy are very limited (Nüssgens et al. 1993; Stafford et al. 2005; Kozaki et al. 2014). The present case is, therefore, a rare case of Graves' ophthalmopathy which deteriorated to dysthyroid optic neuropathy during the third trimester.

Clinical features of Graves' hyperthyroidism have been reported to improve generally in the second and third trimesters, and rebound in the postpartum period (Mestman et al. 1995; Rotondi et al. 2008). However, it is unclear whether clinical features of Graves' ophthalmopathy improve or get worse during pregnancy (Nüssgens et al. 1993; Stafford et al. 2005; Abbouda et al. 2014; Kozaki et al. 2014; Wall et al. 2015). Wall et al. (2015) reported clinical features of thyroid autoimmunity and ophthalmopathy in 7 pregnant patients with Graves' hyperthyroidism. Out of the 7 patients, two had ophthalmopathy, and three had upper eyelid retraction at the onset of pregnancy, respectively. During pregnancy, 5 patients developed mild ophthalmopathy and two patients developed new upper eyelid retraction. In the postpartum period, eye scores improved in 3 patients, remained stable in 2 patients and worsened in 2 patients. These data suggested that the clinical feature of Graves' ophthalmopathy may get worse during pregnancy, like our case.

Graves' ophthalmopathy is an autoimmune disorder characterized by autoimmunity against the TSH receptor in the orbit. TSH receptor present in the orbital tissues is thought to be the primary target of autoimmune reactions in Graves' ophthalmopathy (Hiromatsu et al. 1996; Bahn 2010). TSAb and TSH binding inhibitory antibodies have been reported to be associated with the development of Graves' ophthalmopathy, respectively (Noh et al. 2000; Eckstein et al. 2006; Lytton et al. 2010). Furthermore, TSAb level was found to be directly associated with CAS and clinical severity of Graves' ophthalmopathy (Lytton et al. 2010).

Treatment with anti-thyroid drugs results in a reduction of TRAb concentrations, depending on the dosage and length of treatment (Bech and Nistrup Madsen 1980; McGregor et al. 1980; Tamai et al. 1980; Romaldini et al. 1983; Weetman et al. 1984, 1992; Allannic et al. 1990; Reinwein et al. 1993). Higher doses and longer periods of treatment with anti-thyroid drugs are more effective in lowering TRAb levels (Tamai et al. 1980; Romaldini et al. 1983; Allannic et al. 1990; Ford et al. 1991). However, anti-thyroid drugs are not considered to be disease-modifying treatments in Graves' ophthalmopathy (Wiersinga and Bartalena 2002). We did not treat the patient with anti-thyroid drugs at the 29th week of gestation partly because antithyroid drugs have possible adverse effects on the patient and the fetus, and partly because the effectiveness of antithyroid drugs on Graves' ophthalmopathy has not been established. However, we could not deny the possibility that the treatment with anti-thyroid drugs beginning at the 29th week of gestation decreased TRAb levels and prevented aggravation of the Graves' ophthalmopathy during the third trimester.

Methylprednisolone pulse therapy was also considered 
for the treatment of Graves' ophthalmopathy during the third trimester in this case. However, it was not done because of possible adverse effects of glucocorticoids on the fetus and mother during pregnancy. Treatment of glucocorticoids including methylprednisolone during the third trimester of gestation may be associated with a reduction in birth weight and head circumference (Thorp et al. 2002). Glucocorticoid therapy during pregnancy may increase the risk of premature rupture of the membranes, intrauterine growth restriction (Guller et al. 1995; Lockwood et al. 1996; Thorp et al. 2002), and dysfunction of the fetal hypothalamic-pituitary-adrenal axis (Reynolds 2013). Moreover, glucocorticoid therapy may increase the risk of hypertensive disorder of pregnancy, gestational diabetes, osteoporosis, thrombosis, psychiatric disturbance and infection in mothers (Park-Wyllie et al. 2000).

Glucocorticoids easily cross the placenta (Levitz et al. 1978), but the maternal derived glucocorticoids are metabolized within the placenta by $11 \beta$-hydroxysteroid dehydrogenase-2 (11 $\beta$-HSD2) which converts cortisol, prednisone, and methylprednisolone into inactive products while dexamethasone and betamethasone are less well metabolized (Brown et al. 1993, 1996). Anderson et al. (1981) reported that the methylprednisolone concentration ratio of maternal and cord plasma was 1.37-3.56 (mean 2.24) : 1 . On the other hand, prednisolone concentration ratio of maternal and cord plasma is 8-10: 1 (Beitins et al. 1972). Prednisolone is therefore preferable to methylprednisolone when glucocorticoids are used during pregnancy. In addition, there have been no reports which proved the safety of methylprednisolone pulse therapy during pregnancy.

Recently, acute liver damage and a risk of life-threatening liver failure have been reported after methylprednisolone pulse therapy in association with very high cumulative doses in approximately $0.8 \%$ of patients (Weissel and Hauff 2000; Marinó et al. 2004). Intravenous glucocorticoids are safe if the cumulative dose is less than $8 \mathrm{~g}$ methylprednisolone in one course of therapy (Le Moli et al. 2007). For that reason, EUGOGO recommended the cumulative dose should not exceeded $8 \mathrm{~g}$ with the exception of sight-threating Graves' ophthalmopathy (Zang et al. 2011). In our case, the EUGOGO classification of severity was sightthreating Graves' ophthalmopathy, and therefore, we used a cumulative dose of $9 \mathrm{~g}$ methylprednisolone for the treatment.

In addition to methylprednisolone pulse therapy, we did retrobulbar injections of betamethasone valerate because of the presence of dysthyroid optic neuropathy. Beneficial effects of the local injection therapy of glucocorticoids (peribulbar or retrobulbar injection) on Graves' ophthalmopathy have been reported in the previous reports (Gebertt 1961; Thomas and Hart 1974; Ebner et al. 2004; Goldberg 2004; Bordaberry et al. 2009; Alkawas et al. 2010). Retrobulbar glucocorticoid injection reduces muscle and soft-tissue edema, thus decreasing the optic nerve compression with consequent improvement of optic neuropathy
(Bordaberry et al. 2009).

We present a case of Graves' ophthalmopathy, which was diagnosed as moderate-to-severe ophthalmopathy in the 29th week of gestation, and then deteriorated to sightthreatening dysthyroid optic neuropathy. The records of this case raise the possibility that the clinical features of Graves' ophthalmopathy may get worse to sight-threatening ophthalmopathy during pregnancy. The present case also shows that the glucocorticoid therapies performed one week after delivery is effective against dysthyroid optic neuropathy. Treatment protocols for pregnant patients with Graves' ophthalmopathy which could be deteriorated to sightthreatening dysthyroid optic neuropathy during pregnancy should be established.

\section{Conflict of Interest}

The authors declare no conflict of interest.

\section{References}

Abbouda, A., Trimboli, P. \& Bruscolini, A. (2014) A mild Grave's ophthalmopathy during pregnancy. Semin. Ophthalmol., 29, $8-10$.

Alkawas, A.A., Hussein, A.M. \& Shahien, E.A. (2010) Orbital steroid injection versus oral steroid therapy in management of thyroid-related ophthalmopathy. Clin. Exp. Ophthalmol., 38, 692-697.

Allannic, H., Fauchet, R., Orgiazzi, J., Madec, A.M., Genetet, B., Lorcy, Y., Le Guerrier, A.M., Delambre, C. \& Derennes, V. (1990) Antithyroid drugs and Graves' disease: a prospective randomized evaluation of the efficacy of treatment duration. $J$. Clin. Endocrinol. Metab., 70, 675-679.

Anderson, G.G., Rotchell, Y. \& Kaiser, D.G. (1981) Placental transfer of methylprednisolone following maternal intravenous administration. Am. J. Obstet. Gynecol., 140, 699-701.

Bahn, R.S. (2010) Graves' ophthalmopathy. N. Engl. J. Med., 362, 726-738.

Bartalena, L., Baldeschi, L., Dickinson, A., Eckstein, A., KendallTaylor, P., Marcocci, C., Mourits, M., Perros, P., Boboridis, K., Boschi, A., Currò, N., Daumerie, C., Kahaly, G.J., Krassas, G.E., Lane, C.M., et al. (2008) Consensus statement of the European Group on Graves' orbitopathy (EUGOGO) on management of GO. Eur. J. Endocrinol., 158, 273-285.

Bartalena, L., Pinchera, A. \& Marcocci, C. (2000) Management of Graves' ophthalmopathy: reality and perspectives. Endocr. Rev., 21, 168-199.

Bartalena, L. \& Tanda, M.L. (2009) Clinical practice. Graves' ophthalmopathy. N. Engl. J. Med., 360, 994-1001.

Bech, K. \& Nistrup Madsen, S. (1980) Influence of treatment with radioiodine and propylthiouracil on thyroid stimulating immunoglobulins in Graves' disease. Clin. Endocrinol. (Oxf.), 13, 417-424.

Beitins, I.Z., Bayard, F., Ances, I.G., Kowarski, A. \& Migeon, C.J. (1972) The transplacental passage of prednisone and prednisolone in pregnancy near term. J. Pediatr., 81, 936-945.

Bordaberry, M., Marques, D.L., Pereira-Lima, J.C., Marcon, I.M. \& Schmid, H. (2009) Repeated peribulbar injections of triamcinolone acetonide: a successful and safe treatment for moderate to severe Graves' ophthalmopathy. Acta Ophthalmol., 87, 58-64.

Brown, R.W., Chapman, K.E., Edwards, C.R. \& Seckl, J.R. (1993) Human placental 11 beta-hydroxysteroid dehydrogenase: evidence for and partial purification of a distinct NAD-dependent isoform. Endocrinology, 132, 2614-2621.

Brown, R.W., Diaz, R., Robson, A.C., Kotelevtsev, Y.V., Mullins, J.J., Kaufman, M.H. \& Seckl, J.R. (1996) The ontogeny of 11 
beta-hydroxysteroid dehydrogenase type 2 and mineralocorticoid receptor gene expression reveal intricate control of glucocorticoid action in development. Endocrinology, 137, 794-797.

Burch, H.B. \& Wartofsky, L. (1993) Graves' ophthalmopathy: current concepts regarding pathogenesis and management. Endocr. Rev., 14, 747-793.

Dolman, P.J. (2020) Dysthyroid optic neuropathy: evaluation and management. J. Endocrinol. Invest., doi: 10.1007/s40618020-01361-y. [Epub ahead of print].

Ebner, R., Devoto, M.H., Weil, D., Bordaberry, M., Mir, C., Martinez, H., Bonelli, L. \& Niepomniszcze, H. (2004) Treatment of thyroid associated ophthalmopathy with periocular injections of triamcinolone. Br. J. Ophthalmol., 88, 13801386.

Eckstein, A.K., Plicht, M., Lax, H., Neuhäuser, M., Mann, K., Lederbogen, S., Heckmann, C., Esser, J. \& Morgenthaler, N.G. (2006) Thyrotropin receptor autoantibodies are independent risk factors for Graves' ophthalmopathy and help to predict severity and outcome of the disease. J. Clin. Endocrinol. Metab., 91, 3464-3470.

Ford, H.C., Feek, C.M. \& Delahunt, J.W. (1991) Once daily, low dose, short term antithyroid drug treatment of Graves' disease is followed by an unacceptably high relapse rate. NZ Med. J., 104, 97-98.

Gebertt, S. (1961) Depot-methylprednisolone for subconjunctival and retrobulbar injections. Lancet, 2, 344-345.

Goldberg, R.A. (2004) Orbital steroid injections. Br. J. Ophthalmol., 88, 1359-1360.

Guller, S., Kong, L., Wozniak, R. \& Lockwood, C.J. (1995) Reduction of extracellular matrix protein expression in human amnion epithelial cells by glucocorticoids: a potential role in preterm rupture of the fetal membranes. J. Clin. Endocrinol. Metab., 80, 2244-2250.

Hiromatsu, Y., Sato, M., Inoue, Y., Koga, M., Miyake, I., Kameo, J., Tokisawa, S., Yang, D. \& Nonaka, K. (1996) Localization and clinical significance of thyrotropin receptor mRNA expression in orbital fat and eye muscle tissues from patients with thyroid-associated ophthalmopathy. Thyroid, 6, 553-562.

Kozaki, A., Nakamura, H., Inoue, R. \& Inoue, T. (2014) Dysthyroid optic neuropathy in pregnancy. Nippon Ganka Gakkai Zasshi, 118, 433-439.

Le Moli, R., Baldeschi, L., Saeed, P., Regensburg, N., Mourits, M.P. \& Wiersinga, W.M. (2007) Determinants of liver damage associated with intravenous methylprednisolone pulse therapy in Graves' ophthalmopathy. Thyroid, 17, 357-362.

Levitz, M., Jansen, V. \& Dancis, J. (1978) The transfer and metabolism of corticosteroids in the perfused human placenta. Am. J. Obstet. Gynecol., 132, 363-366.

Lockwood, C.J., Radunovic, N., Nastic, D., Petkovic, S., Aigner, S. \& Berkowitz, G.S. (1996) Corticotropin-releasing hormone and related pituitary-adrenal axis hormones in fetal and maternal blood during the second half of pregnancy. $J$. Perinat. Med., 24, 243-251.

Lytton, S.D., Ponto, K.A., Kanitz, M., Matheis, N., Kohn, L.D. \& Kahaly, G.J. (2010) A novel thyroid stimulating immunoglobulin bioassay is a functional indicator of activity and severity of Graves'orbitopathy. J. Clin. Endocrinol. Metab., 95, 21232131.

Marcocci, C., Bartalena, L., Bogazzi, F., Panicucci, M. \& Pinchera, A. (1989) Studies on the occurrence of ophthalmopathy in Graves' disease. Acta Endocrinol. (Copenh.), 120, 473-478.

Marinó, M., Morabito, E., Brunetto, M.R., Bartalena, L., Pinchera, A. \& Marocci, C. (2004) Acute and severe liver damage associated with intravenous glucocorticoid pulse therapy in patients with Graves' ophthalmopathy. Thyroid, 14, 403-406.

McGregor, A.M., Petersen, M.M., McLachlan, S.M., Rooke, P., Smith, B.R. \& Hall, R. (1980) Carbimazole and the autoimmune response in Graves' disease. N. Engl. J. Med., 303, 302-307.
Mestman, J.H., Goodwin, T.M. \& Montoro, M.M. (1995) Thyroid disorders of pregnancy. Endocrinol. Metab. Clin. North Am., 24, 41-71.

Nüssgens, Z., Roggenkämper, P. \& Schweikert, H.U. (1993) Development of endocrine orbitopathy in pregnancy. Klin. Monbl. Augenheilkd., 202, 130-133.

Noh, J.Y., Hamada, N., Inoue, Y., Abe, Y., Ito, K. \& Ito, K. (2000) Thyroid-stimulating antibody is related to Graves' ophthalmopathy, but thyrotropin-binding inhibitor immunoglobulin is related to hyperthyroidism in patients with Graves' disease. Thyroid, 10, 809-813.

Park-Wyllie, L., Mazzotta, P., Pastuszak, A., Moretti, M.E., Beique, L., Hunnisett, L., Friesen, M.H., Jacobson, S., Kasapinovic, S., Chang, D., Diav-Citrin, O., Chitayat, D., Nulman, I., Einarson, T.R. \& Koren, G. (2000) Birth defects after maternal exposure to corticosteroids: prospective cohort study and metaanalysis of epidemiological studies. Teratology, 62, 385-392.

Reinwein, D., Benker, G., Lazarus, J.H. \& Alexander, W.D. (1993) A prospective randomized trial of antithyroid drug dose in Graves' disease therapy. European Multicenter Study Group on Antithyroid Drug Treatment. J. Clin. Endocrinol. Metab., 76, 1516-1521.

Reynolds, R.M. (2013) Programming effects of glucocorticoids. Clin. Obstet. Gynecol., 56, 602-609.

Romaldini, J.H., Bromberg, N., Werner, R.S., Tanaka, L.M., Rodrigues, H.F., Werner, M.C., Farah, C.S. \& Reis, L.C. (1983) Comparison of effects of high and low dosage regimens of antithyroid drugs in the management of Graves' hyperthyroidism. J. Clin. Endocrinol. Metab., 57, 563-570.

Rotondi, M., Cappelli, C., Pirali, B., Pirola, I., Magri, F., Fonte, R., Castellano, M., Rosei, E.A. \& Chiovato, L. (2008) The effect of pregnancy on subsequent relapse from Graves' disease after a successful course of antithyroid drug therapy. J. Clin. Endocrinol. Metab., 93, 3985-3988.

Stafford, I.P., Dildy, G.A. 3rd \& Miller, J.M. Jr. (2005) Severe Graves' ophthalmopathy in pregnancy. Obstet. Gynecol., 105, 1221-1223.

Tamai, H., Nakagawa, T., Fukino, O., Ohsako, N., Shinzato, R., Suematsu, H., Kuma, K., Matsuzuka, F. \& Nagataki, S. (1980) Thionamide therapy in Graves' disease: relation of relapse rate to duration of therapy. Ann. Intern. Med., 92, 488-490.

Thomas, I.D. \& Hart, J.K. (1974) Retrobulbar repository corticosteroid therapy in thyroid ophthalmopathy. Med. J. Aust., 2, 484-487.

Thorp, J.A., Jones, P.G., Knox, E. \& Clark, R.H. (2002) Does antenatal corticosteroid therapy affect birth weight and head circumference? Obstet. Gynecol., 99, 101-108.

Tramunt, B., Imbert, P., Grunenwald, S., Boutault, F. \& Caron, P. (2019) Sight-threatening Graves' orbitopathy: twenty years' experience of a multidisciplinary thyroid-eye outpatient clinic. Clin. Endocrinol. (Oxf.), 90, 208-213.

Wall, J.R., Lahooti, H., Hibbert, E.J. \& Champion, B. (2015) Relationship between clinical and immunological features of thyroid autoimmunity and ophthalmopathy during pregnancy. J. Thyroid Res., 2015, 698470.

Weetman, A.P., McGregor, A.M. \& Hall, R. (1984) Evidence for an effect of antithyroid drugs on the natural history of Graves' disease. Clin. Endocrinol. (Oxf.), 21, 163-172.

Weetman, A.P., Tandon, N. \& Morgan, B.P. (1992) Antithyroid drugs and release of inflammatory mediators by complementattacked thyroid cells. Lancet, 340, 633-636.

Weissel, M. \& Hauff, W. (2000) Fatal liver failure after high-dose glucocorticoid pulse therapy in a patient with severe thyroid eye disease. Thyroid, 10, 521 .

Wiersinga, W.M. \& Bartalena, L. (2002) Epidemiology and prevention of Graves' ophthalmopathy. Thyroid, 12, 855-860.

Zang, S., Ponto, K.A. \& Kahaly, G.J. (2011) Clinical review: intravenous glucocorticoids for Graves' orbitopathy: efficacy and morbidity. J. Clin. Endocrinol. Metab., 96, 320-332. 